\title{
GERMINACIÓN DE ESTADOS DE RESISTENCIA DE DIATOMEAS Y DINOFLAGELADOS EN SEDIMENTOS MARINOS DE DOS ÁREAS DE SURGENCIA DE CHILE
}

\author{
GERMINATION OF RESTING STAGES OF DIATOMS AND \\ DINOFLAGELLATES IN MARINE SEDIMENTS FROM TWO UPWELLING \\ AREAS OF CHILE
}

\author{
Gloria E. Sánchez ${ }^{1,2}$, Diana Sarno ${ }^{3}$, Marina Montresor ${ }^{3}$, \\ Raffaele Siano ${ }^{3} \&$ Carina B. Lange ${ }^{2,4}$
}

\begin{abstract}
${ }^{1}$ Programa Doctorado en Ciencias Biológicas Mención Botánica, Departamento de Botánica, Universidad de Concepción, Casilla 160-C, Concepción, Chile; ${ }^{2}$ Centro de Investigación Oceanográfica en el Pacífico Sur-Oriental (FONDAP-COPAS), Universidad de Concepción, Casilla 160-C, Concepción, Chile; ${ }^{3}$ Stazione Zoologica Anton Dohrn, Villa Comunale, 80121 Nápoles, Italia; ${ }^{4}$ Departamento de Oceanografía, Universidad de Concepción, Casilla 160-C, Concepción, Chile glsanchez@udec.cl
\end{abstract}

\begin{abstract}
RESUMEN
Con el fin de evaluar la potencial germinación de los estados de resistencia de las diatomeas y dinoflagelados preservados en sedimentos superficiales, se cultivaron bajo condiciones de laboratorio sedimentos de las bahías de Mejillones $\left(23^{\circ} \mathrm{S}\right)$ y Concepción $\left(36^{\circ} \mathrm{S}\right)$, Chile: Ciclo L:O 12:12 h, intensidad de luz $140 \mu \mathrm{mol} \mathrm{m}^{2} \mathrm{~s}^{-1}$, temperatura ambiente y 35,4 unidades de salinidad. Las principales especies de diatomeas presentes en los sedimentos fueron Skeletonema japonicum y esporas de Chaetoceros. Los quistes de dinoflagelados estuvieron representados por Diplopsalis, Scrippsiella, Woloszynskia y las especies Protoperidinium avellanum y P. leonis. Después de 20 días de cultivo, se registró germinación y crecimiento de $S$. japonicum y de varias especies de Chaetoceros, sin embargo su abundancia fue baja. Las diatomeas con crecimiento abundante fueron Stauroneis legleri, Pseudostaurosira trainorii, Pseudostaurosira sp. 1, Pseudostaurosira sp. 2 y Navicula pseudoreinhardtii. El dinoflagelado Woloszynskia sp. también germinó y creció abundantemente. Este trabajo incluye una breve descripción de las especies cultivadas y algunos aspectos de su ecología. Se discuten las posibles causas de la pobre germinación de las diatomeas planctónicas, siendo la baja concentración de oxígeno disuelto en las aguas de fondo uno de los principales factores que presumiblemente afectaron la sobrevivencia de las esporas de resistencia.
\end{abstract}

Palabras clave: Diatomeas, dinoflagelados, estados de resistencia, cultivos, sedimentos, Chile.

\section{ABSTRACT}

With the aim to assess germination of diatom and dinoflagellates resting spores we cultured under laboratory conditions surface sediments collected in the Mejillones Bay $\left(23^{\circ} \mathrm{S}\right)$ and off Concepción (36 $\left.\mathrm{S}\right)$, Chile. These sediments were cultured in the laboratory with a $12: 12 \mathrm{~h} \mathrm{~L} / \mathrm{D}$ cycle, light intensity of $140 \mu \mathrm{mol} \mathrm{m}^{2} \mathrm{~s}^{-1}$, at room temperature, and with a salinity of 35.4 units. The main diatom species in the sediments were Skeletonema japonicum and Chaetoceros spores. Dinoflagellate cysts were represented by the genera Diplopsalis, Scrippsiella, and Woloszynskia and the species Protoperidinium avellanum and P. leonis. After 20 days of culturing, germination and growth was recorded for $S$. japonicum and several of the Chaetoceros species, although their abundance was low. The diatoms with abundant growth were Stauroneis legleri, Pseudostaurosira trainorii, Pseudostaurosira sp.1, Pseudostaurosira sp. 2, and Navicula pseudoreinhardtii. The dinoflagellate Woloszynskia sp. also germinated and grew abundantly in the culture. This study includes a brief description of the cultured species and some aspects of their ecology. In addition, we discuss 
Gayana Bot. 66(2), 2009

the possible causes for low levels of germination in planktonic diatoms, finding low dissolved oxygen concentrations in the bottom waters to be one of the main factors that presumably affected the survival of resting spores in the sediment.

KEYwords: Diatoms, dinoflagellates, resting stages, cultures, sediments, Chile.

\section{INTRODUCCION}

En los sedimentos marinos de la plataforma y del talud continental de Chile se ha reportado la presencia de esporas de resistencia de diatomeas (Romero et al. 2001) y dinoflagelados (Lembeye 2004, Salgado 2004), evidenciando una estrecha relación entre la columna de agua y los sedimentos. Se sabe que el ciclo de vida de un amplio número de especies planctónicas incluye la formación de quistes, esporas o células de resistencia (Garrison 1981, McQuoid \& Hobson 1996). La abundancia y diversidad de especies que forman este tipo de células es un aspecto importante en la dinámica de la comunidad fitoplanctónica y un fuerte vínculo entre las comunidades planctónicas y bentónicas (Garrison 1981, Marcus \& Boero 1998).

En diatomeas marinas, la formación de esporas de resistencia está asociada a condiciones de baja concentración de nutrientes, especialmente de nitratos, en los estadios finales del "bloom" primaveral (Garrison 1981, McQuoid 2002). Estas formas de resistencia pueden proporcionar la semilla y los subsecuentes "blooms" cuando las condiciones son favorables para la división celular (Hargraves \& French 1975, Garrison 1981). Las esporas son más resistentes al pastoreo (Hargraves \& French 1975) y son exportadas más rápidamente que las células vegetativas, desde la zona fótica a los sedimentos (Garrison 1981, Hollibaugh et al. 1981). Además, tanto las esporas como las células de resistencia soportan mejor que sus parentales, condiciones de crecimiento desfavorables (ver revisión en McQuoid \& Hobson 1995). En los dinoflagelados, su ciclo de vida es similar al de las diatomeas en cuanto a que incluye células vegetativas, células sexuales y en algunos casos formas de resistencia (quistes). Los quistes de dinoflagelados cumplen funciones de protección, de recombinación genética, de propagación y/o de dispersión (Anderson et al. 1995).

El tiempo de sobrevivencia de los estados de resistencia de algunas especies de diatomeas y dinoflagelados es variable, en un rango que puede ir desde meses a años. Incubaciones en el laboratorio sugieren que el tiempo de sobrevivencia de más de dos años es común en muchas especies costeras (Lewis et al. 1999, Anil et al. 2007), incluso en algunos casos puede superar varias décadas (McQuoid et al. 2002).

Quistes de varias especies de fitoplancton han sido introducidos en diversos ambientes, transportados en agua de lastre y sedimentos asociados; algunas de estas especies introducidas han afectado las especies locales, llegando a tener importantes repercusiones económicas y ecológicas (Awad et al. 2004).

La sobrevivencia de quistes y/o esporas de resistencia depositadas en sedimentos marinos de Chile, así como la potencial incidencia de su germinación sobre la dinámica del fitoplancton en la columna de agua, ha sido pobremente estudiada. El objetivo del presente estudio consistió en la realización de cultivos de estados de resistencia de algunas diatomeas y dinoflagelados preservados en sedimentos superficiales marinos a fin de determinar y discutir factores ambientales que podrían haber condicionado su germinación. Este es el primer trabajo sobre el cultivo de estados de resistencia de diatomeas en sedimentos de la plataforma continental chilena, donde se obtuvieron resultados positivos en germinación y crecimiento. La exitosa germinación de quistes de dinoflagelados provenientes de sedimentos marinos de la región sur-austral de Chile ya fue reportada con anterioridad por Lembeye (2004).

\section{MATERIALES Y METODOS}

\section{AREAS DE ESTUDIO}

A lo largo de la costa de Chile se han identificado seis centros de surgencia, ubicados en Arica, Iquique, Antofagasta-Mejillones, Coquimbo, Valparaíso y Talcahuano-Golfo de Arauco (Fonseca \& Farías 1987). Entre los $18^{\circ}$ y $35^{\circ} \mathrm{S}$ los vientos favorables a la surgencia están presentes durante todo el año; mientras que entre los $35^{\circ}$ y $38^{\circ} \mathrm{S}$, éstos están restringidos al verano austral (Strub et al. 1998). Este trabajo se limitó a dos centros de 
surgencia, Mejillones $\left(23^{\circ} \mathrm{S}\right)$ y Concepción $\left(36^{\circ}\right.$ S). En Mejillones el sistema de surgencia de Punta Angamos transporta altas biomasas al interior de la Bahía de Mejillones (producción primaria promedio 2,9 $\mathrm{g} \mathrm{C} \mathrm{m}^{-2} \mathrm{día}^{-1}$ ) (Marín et al. 1993). En la zona norte de Chile la plataforma continental es muy angosta (Strub et al. 1998) y la zona mínima de oxígeno (ZMO) está bien desarrollada, lo que en parte ha permitido la formación de sedimentos laminados (Valdés et al. 2000); aquí la oxiclina $\left(1 \mathrm{ml} \mathrm{L}^{-1}\right)$ se ubica entre los 20 y los $120 \mathrm{~m} \mathrm{de}$ profundidad (Morales et al. 1999). Esta región se caracteriza por ser una zona muy árida con escaso aporte fluvial (www.meteochile.cl).

En Concepción, la surgencia se da en toda la costa, especialmente en Punta Lavapié donde afloran aguas con temperatura $<12^{\circ} \mathrm{C}$ y se forman filamentos de aguas frías que se extienden costa afuera (Fonseca \& Farías 1987). Treinta kilómetros fuera de la costa (en la Estación 18), por ejemplo, la producción primaria en promedio es de $2,7 \mathrm{~g} \mathrm{C} \mathrm{m}^{-}$ ${ }^{2}$ día $^{-1}$ (Serie de Tiempo FONDAP-COPAS 2004). Una parte de esta productividad es exportada desde la zona fótica hacia los sedimentos, siendo las diatomeas el grupo que mayor aporte hace tanto a la productividad primaria en la columna de agua, como a la fracción que es exportada al fondo (González et al. 2007). En esta área, la oxiclina $\left(1 \mathrm{ml} \mathrm{L}^{-1}\right)$ varía estacionalmente, y se ubica entre los $24 \mathrm{~m}$ (verano) y $65 \mathrm{~m}$ (invierno) de profundidad (Escribano et al. 2007). La plataforma continental adyacente a la Bahía de Concepción está limitada al norte por el cañón submarino del Río Itata y al sur por el cañón submarino del Río Bío-Bío (Cáceres \& Arcos 1991). Los sedimentos son limosos, poco arcillosos, de color gris-pardo y ricos en materia orgánica. Una capa floculenta (de grosor variable) se forma en la interfase aguasedimento y está compuesta principalmente por fitodetrito (Gutiérrez et al. 2000).

RECOLECCIÓN DE MUESTRAS Y ANÁlisis DE LABORATORIO

Los sedimentos de la Bahía de Mejillones $\left(23^{\circ}\right.$ $02,6^{\prime} \mathrm{S}$ ) fueron recolectados con un sacatestigos múltiple (multicorer), a bordo del AGOR Vidal Gormáz en septiembre de 2005. Frente a la Bahía de Concepción $\left(36^{\circ} 30,8^{\prime} \mathrm{S}\right)$, los sedimentos se recolectaron con un sacatestigo de caja (box corer) a bordo de la lancha oceanográfica Kay-Kay durante el año 2005 en el marco de la serie de tiempo del
Centro FONDAP-COPAS (Tabla I). Los testigos de sedimento fueron cortados en intervalos de $0,5 \mathrm{~cm}$ y almacenados a $4{ }^{\circ} \mathrm{C}$ y en condiciones de oscuridad hasta su posterior análisis. Las muestras analizadas en este trabajo corresponden a la capa floculenta (sedimento no consolidado) y los primeros $0,5 \mathrm{~cm}$ de la columna sedimentaria (Tabla I).

Para el estudio de las diatomeas una parte de la muestra fue liofilizada; de ella, 0,5 g de sedimento fueron procesados según metodología de Schrader \& Gersonde (1978). Posteriormente, una alícuota de la muestra limpia fue depositada en placas permanentes y montada con resina Naphrax. Las especies fueron identificadas utilizando un microscopio Zeiss Axioskop 2 plus con contraste de fase. Para la estimación cuantitativa se contaron mínimo 300 valvas a lo largo de transectas pre-definidas en cada placa. La identificación de las especies se fundamentó en los trabajos de Rivera (1968), Cupp (1943), Round et al. (1990), Hustedt (1930), Sims (1996), Tomas (1997) y Witkowski et al. (2000). Para el estudio de los quistes de dinoflagelados, se siguió la metodología de Bolch (1997) que incluye la concentración y separación de éstos del sedimento húmedo. Posteriormente, los quistes fueron identificados utilizando un microscopio Zeiss Axiophot con contraste de fase, contraste de interferencia diferencial y epifluorescencia. Las fotografías fueron tomadas con el sistema digital Zeiss AxioCam, acoplado a este microscopio. La identificación se basó en los trabajos morfológicos y taxonómicos de Wall \& Dale (1968), Lewis et al. (1984), Matsuoka (1988) y Matsuoka \& Fukuyo (2000).

Los experimentos de cultivo fueron realizados entre febrero y marzo de 2007 en la Stazione Zoologica Anton Dohrn (SZ) en Nápoles, Italia. Para ello, un gramo de sedimento húmedo de cada muestra fue diluido en $10 \mathrm{ml}$ de medio f/4 (Amato et al. 2005). De esta solución, homogeneizada, se tomaron $200 \mu \mathrm{l}$ que fueron llevados a cuatro diluciones sucesivas en microplacas, también con medio $\mathrm{f} / 4$, para obtener una concentración final de 200, 20, 2 y $0,2 \mu \mathrm{l}$ de sedimento en cultivo (McQuoid et al. 2002). Las condiciones de laboratorio durante el cultivo fueron: Ciclo L:O 12:12 h, intensidad de luz $140 \mu \mathrm{mol} \mathrm{m} \mathrm{m}^{2} \mathrm{~s}^{-1}$, temperatura ambiente $\mathrm{y}$ 35,4 unidades de salinidad. Estos cultivos fueron controlados cada 3 días, durante 25 días.

Las especies que se desarrollaron en los cultivos fueron aisladas mediante pipeteo 
Gayana Bot. 66(2), 2009

capilar (González et al. 1995) y mantenidas en las condiciones señaladas arriba. Al término del experimento (día 25), las especies aisladas fueron lavadas con agua destilada, limpiadas con ácidos nítrico y fosfórico, y finalmente lavadas con agua destilada en cinco ocasiones para llegar a pH neutro, siguiendo la metodología del Laboratorio de Fitoplancton de la SZ. Este material fue fotografiado en el microscopio electrónico de barrido (MEB) JSM-6700F y con microscopio de luz (ML) Zeiss Axiophot de la SZ, y se presenta en las Figuras 1-7.

\section{RESULTADOS}

Las esporas de Chaetoceros fueron los componentes principales en los sedimentos de ambos sitios de muestreo, Concepción y Mejillones, alcanzando el $\sim 76$ y $85 \%$ del total de diatomeas, respectivamente. Entre las especies de Chaetoceros, C. affinis Lauder 1864, C. constrictus Gran 1897/vanheurckii Gran 1897, C. coronatus Gran 1897, C. diadema (Ehrenberg) Gran 1897, C. debilis Cleve 1894, C. didymus Ehrenberg 1845, C. lauderi Ralfs 1864 y C. radicans Schütt 1895/cinctus Gran 1897 fueron las dominantes, acompañadas por Skeletonema japonicum Zingone \& Sarno $2005 \quad(4 \%$ en Concepción y $2 \%$ en Mejillones; Fig. 1).

Los quistes de dinoflagelados estuvieron representados por las especies del género Protoperidinium Bergh $1882 \quad$ P. avellanum (Meunier 1919) Balech 1974 y P. leonis (Pavillard) Balech 1974, y una especie no identificada (Protoperidinium sp.), y los géneros Diplopsalis Bergh 1881, Scrippsiella Balech ex Loeblich III 1965 y Woloszynskia Thompson 1951 (Fig. 2A-F).

Después de 20 días de cultivo, se registró crecimiento de Skeletonema japonicum, Paralia sulcata(Ehrenberg) Cleve 1873 y de varias especies de Chaetoceros, sin embargo su abundancia fue baja. Las diatomeas Navicula pseudoreinhardtii Patrick 1959, Stauroneis legleri Hustedt 1959 y tres especies de Pseudostaurosira (Grunow) Williams et Round 1987, P. trainorii Morales 2008 y dos no identificadas (Pseudostaurosira sp. 1 y Pseudostaurosira sp. 2), fueron las especies que crecieron abundantemente. Adicionalmente, germinó el dinoflagelado Woloszynskia sp. (Fig. 2G-I) y una cianobacteria cocoide (Tabla II).

A continuación se da una breve descripción de estas diatomeas, y en la Tabla III se resumen las medidas morfométricas de los frústulos y las valvas fotografiadas en el MEB.

TABLA I. Origen y fecha de recolección de las muestras de sedimento usadas en este estudio.

TABLE I. Origin and collection date of sediment samples used in this study.

\begin{tabular}{lccc}
\hline \multirow{2}{*}{$\begin{array}{l}\text { Año 2005/ } \\
\text { Meses }\end{array}$} & \multicolumn{2}{c}{ Concepción } & Bahía de Mejillones \\
\cline { 2 - 4 } & Capa floculenta & 0 a $0,5 \mathrm{~cm}$ & 0 a $0,5 \mathrm{~cm}$ \\
\hline Febrero & $\mathrm{X}$ & $\mathrm{X}$ & \\
Marzo & $\mathrm{X}$ & & $\mathrm{X}$ \\
Septiembre & $\mathrm{X}$ & $\mathrm{X}$ & \\
Noviembre & & & \\
Diciembre & $\mathrm{X}$ & & \\
\hline
\end{tabular}


Cultivo de diatomeas y dinoflagelados en sedimentos marinos: SÁnchEZ, G. ET AL.

TABLA II. Resumen de la germinación de diatomeas y de un dinoflagelado en cultivo. C: Cianobacteria cocoide, Ch: Chaetoceros spp; Np: Navicula pseudoreinhardtii; Ps: Paralia sulcata; P sp. 1: Pseudostaurosira sp. 1, P sp. 2: Pseudostaurosira sp. 2, Sk: Skeletonema japonicum; Pt: Pseudostaurosira trainorii; Sl: Stauroneis legleri y DW: dinoflagelado Woloszynskia sp.

TABLE II. Summary of diatoms and one dinoflagellate germination in culture. C: Coccoid cyanobacteria, Ch: Chaetoceros spp., Np: Navicula pseudoreinhardtii, Ps: Paralia sulcata, P sp. 1: Pseudostaurosira sp. 1, P sp. 2: Pseudostaurosira sp. 2, Sk: Skeletonema japonicum, Pt: Pseudostaurosira trainorii; Sl: Stauroneis legleri, and DW: the dinoflagellate Woloszynskia sp.

\begin{tabular}{lccc}
\hline \multirow{2}{*}{$\begin{array}{l}\text { Año 2005/ } \\
\text { Meses }\end{array}$} & Capa floculenta & 0 a 0,5 cm & Bahía de Mejillones \\
\cline { 2 - 4 } Febrero & C; Ch; $\mathrm{cm}$ \\
$\begin{array}{l}\text { Marzo } \\
\text { Septiembre }\end{array}$ & C ; P sp. 1; P sp. 2; Ps; Pt; Sl; DW & C; Sk & \\
$\begin{array}{l}\text { Noviembre } \\
\text { Diciembre }\end{array}$ & C; Sk & C; Sk; Ps & C; Np; DW \\
\hline
\end{tabular}

\section{TAXONOMÍA}

Todas las diatomeas que crecieron abundantemente en los cultivos fueron especies representantes de las familias Fragilariaceae, Naviculaceae y Stauroneidaceae. A continuación se presenta la clasificación taxonómica de cada especie según AlgaeBase (http://www.algaebase.org/index.lasso).

\author{
Phylum Bacillariophyta \\ Clase Fragilariophyceae \\ Subclase Fragilariophycidae \\ Orden Fragilariales \\ Familia Fragilariaceae \\ Género Pseudostaurosira \\ Especie Pseudostaurosira trainorii \\ Pseudostaurosira sp. 1 \\ Pseudostaurosira sp. 2 \\ Clase Bacillariophyceae \\ Subclase Fragilariophycidae \\ Orden Naviculales \\ Familia Naviculaceae \\ Género Navicula \\ Especie Navicula pseudoreinhardtii \\ Familia Stauroneidaceae \\ Género Stauroneis \\ Especie Stauroneis legleri
}

\section{DESCRIPCIONES}

\section{Pseudostaurosira trainorii Morales}

(Fig. 3A-F)

Referencias: Morales 2001, 113, Figs. 6a-1.

Descripción: Las células forman cadenas filamentosas (Fig. 3A y B). Las valvas son pequeñas, redondas a linear-elípticas, con ápices redondeados (Fig. 3E y F). Hay una espina sobre cada estría, ubicada entre la cara valvar y el manto (Fig. 3B-D); espinas aplanadas en forma de espátula, con proyecciones laterales, que a veces dan la impresión de espinas aserradas (Fig. 3C y D). Las espinas evidentemente juegan un rol en la formación de cadenas (Fig. 3B y C). Las areolas tanto de la cara valvar como del manto contienen velum ramificado (Fig. 3D y E). En la periferia exterior de las areolas del manto valvar se encuentran pequeños discos aplanados especialmente en las areolas inmediatamente debajo de las espinas (Fig. 3D). En las areolas asociadas con espinas, las proyecciones en forma de disco parecen proceder de la espina. Estrías en cada lado del eje de la valva están opuestas a ligeramente alternadas. Externamente, estrías en la cara valvar se componen de areolas de forma ovalada, en general, disminuyendo su tamaño, desde los márgenes de la valva al centro del esternón o del manto valvar (Fig. 3D-F). En cada polo valvar hay pequeños poros apicales (Fig. 3F). Procesos labiados y rafe ausentes. Cíngulo compuesto de 6 a 8 bandas, valvocopula ligeramente curvada hacia los polos (Fig. 3B-D).

Estudios previos han reportado a $P$. trainorii bajo el nombre de Fragilaria elliptica (Archibald 1983) y Staurosira elliptica (Snoeijs \& Balashova 1998). Las principales características que definen la especie son la ubicación y forma de las espinas (cerca del margen valvar, sobre cada estría y espinas aplanadas en forma de espátula, con proyecciones laterales); además la presencia de 
Gayana Bot. 66(2), 2009
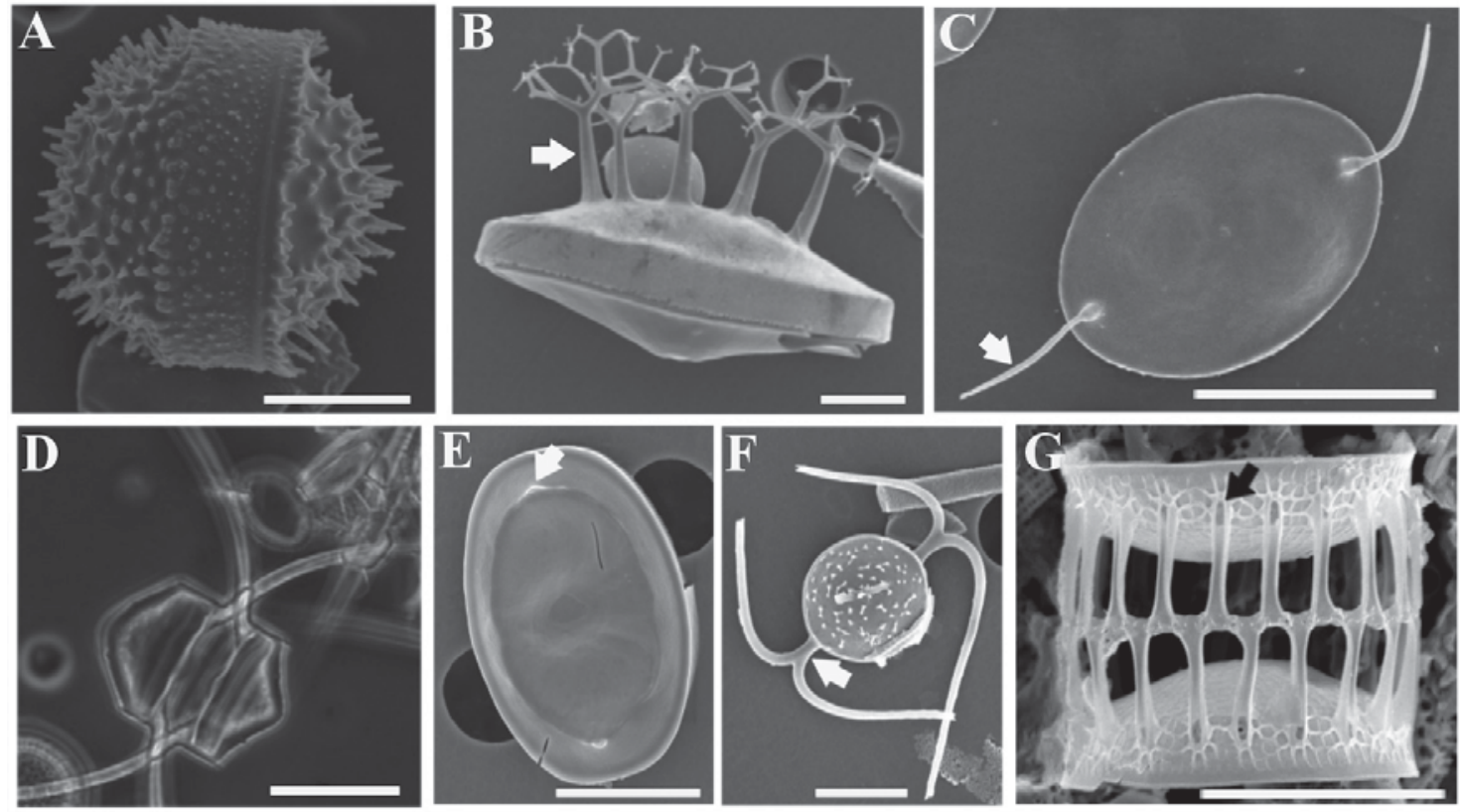

Figura 1. Principales esporas de especies de Chaetoceros acompañadas por valvas intercalares de Skeletonema japonicum en sedimentos frente a Concepción (A, C-E, G) y la bahía de Mejillones (B, F). ML: D; MEB: A-C, E-G. A. Chaetoceros affinis. Espora en vista conectival, ambas valvas con espinas pequeñas. B. C. diadema. Espora en vista conectival; nótese las espinas ramificadas dicotómicamente en la valva primaria (flecha) y la valva secundaria lisa. C. C. debilis. Valva primaria de la espora; nótese las dos setas (flecha). D. C. didymus. Esporas de resistencia apareadas, unidas por las setas. E. C. didymus. Valva secundaria con setas incipientes (flecha) y una protrusión central; nótese la forma rectangular de la espora en vista valvar. F. C. radicans/cinctus. Nótese la fusión de la base de las setas y su curvatura en torno a la espora. G. Skeletonema japonicum. Dos valvas intercalares en vista conectival; note el anillo submarginal de procesos reforzados (flecha negra) y los tubos externos de los procesos reforzados formando una unión tipo 1:2. Escalas: $A-C, E-G=5 \mu \mathrm{m} ; D=20 \mu \mathrm{m}$.

FIGURE 1. Resting spores of most abundant Chaetoceros species accompanied by intercalary valves of Skeletonema japonicum, in sediments off Concepción (A, C-E, G), and Mejillones Bay (B, F). LM: D; SEM: A-C, E-G. A. Chaetoceros affinis. Spore in girdle view; valves with small spines. B. C. diadema. Spore in girdle view; note the dichotomously branching spines on the primary valve (arrow) and the smooth secondary valve. C. C. debilis. Primary valve of the spore; note the presence of the two setae (arrow). D. C. didymus. Paired resting spores, held together by setae. E. C. didymus. Secondary valve with the incipient setae (arrow) and a central protrusion; note the rectangular shape of the spore in valve view. F. C. radicans/cinctus. Note the basal fusion of the setae and their curvature around the spore. G. Skeletonema japonicum. Two intercalary valves in girdle view; note the submarginal ring of fultoportulae (black arrow) and the external tubes of the fultoportulae joined in a 1:2 fashion. Scales: A-C, E-G $=5 \mu \mathrm{m} ; \mathrm{D}=20 \mu \mathrm{m}$. 
Cultivo de diatomeas y dinoflagelados en sedimentos marinos: SÁnCHEZ, G. ET AL.
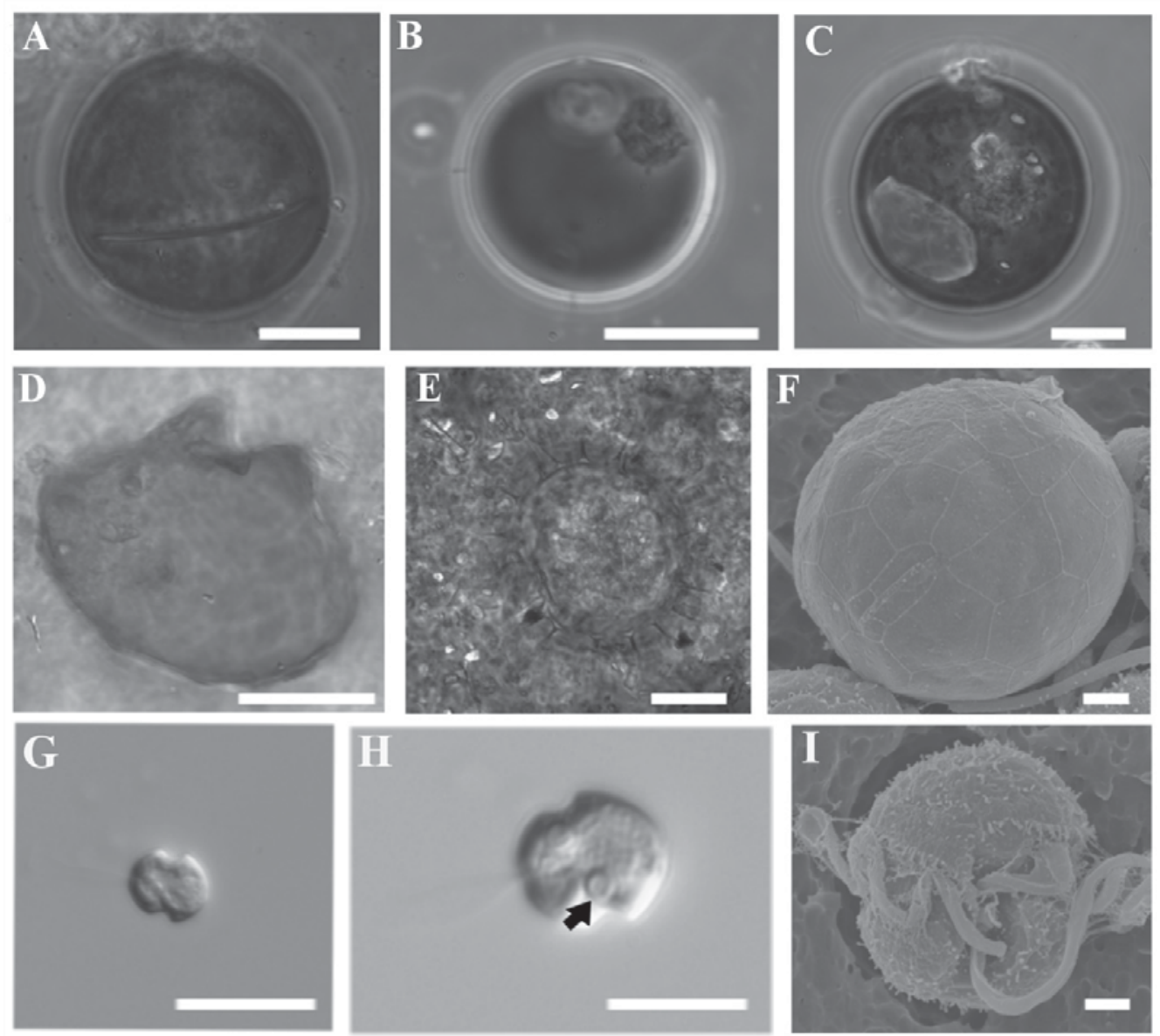

Figura 2. Dinoflagelados en sedimentos de Concepción (A-E) y la bahía de Mejillones (F-I). ML: A-E, G, H; MEB: F, I. Quistes de A. Diplopsalis sp., B. Protoperidinium sp., C. P. avellanum, D. P. leonis, E. Scrippsiella sp. y F. Woloszynskia sp. G-I. Célula vegetativa de Woloszynskia sp. derivadas de la germinación de quistes en los cultivos experimentales. Note las vesículas alveolares y la acrobase recta en Fig. 2F y el pirenoide (flecha negra) en Fig. 2H. Escalas: A-E, $\mathrm{G}-\mathrm{H}=10 \mu \mathrm{m} ; \mathrm{F}, \mathrm{I}=1 \mu \mathrm{m}$.

Figure 2. Dinoflagellates from sediments off Concepción (A-E) and Mejillones Bay (F-I). LM: A-E, G, H; SEM: F, I. Cysts of A. Diplopsalis sp., B. Protoperidinium sp., C. P. avellanum, D. P. leonis, E. Scrippsiella sp., and F. Woloszynskia sp. G-I. Vegetative cell of Woloszynskia sp. germinated the cysts in culture experiments. Note the presence of alveolar vesicles and the straight acrobase in Fig. 2F, and the pyrenoid (black arrow) in Fig. 2H. Scales: A-E, G-H=10 $\mu \mathrm{m}, \mathrm{F}, \mathrm{I}=1 \mu \mathrm{m}$. 
Gayana Bot. 66(2), 2009

TABLA III. Resumen de características de diatomeas penadas que crecieron en cultivo abundantemente. TABLE III. Summary of pennate diatoms that grew abundantly in culture.

\begin{tabular}{ccccc}
\hline Especie & $\begin{array}{c}\text { Eje apical } \\
(\mu \mathrm{m})\end{array}$ & $\begin{array}{c}\text { Eje transapical } \\
(\mu \mathrm{m})\end{array}$ & $\begin{array}{c}\mathrm{N}^{\mathrm{o}} \text { de estrías } \\
\text { en } 10 \mu \mathrm{m}\end{array}$ & Referencia \\
\hline Pseudostaurosira trainorii & $2-4$ & & 25 & Schumann 1867 \\
& $3-10$ & $2,8-6,0$ & $11-20$ & Kelly et al. 2005 \\
& $1,9-8,6$ & $1,7-4,4$ & $20-25$ & Morales 2001 \\
& $6-14$ & $3-3,5$ & $14-16$ & Edlund et al. 2006 \\
Pseudostaurosira sp 1. & $3,7-6,5$ & $3,7-4,6$ & $16-20$ & Este trabajo \\
Pseudostaurosira sp. 2 & $6,6-7,1$ & $2,1-2,4$ & $16-18$ & Este trabajo \\
Navicula pseudoreinhardtii & $22,3-25,2$ & $2,9-3,3$ & $10-11$ & Este trabajo \\
& $15-25$ & $4-7$ & $18-20$ & Patrick 1959 \\
& $16-26$ & $6-7$ & $17-18$ & Rivera \& Valdebenito 1979 \\
Stauroneis legleri & $21-27$ & $7,9-8,3$ & $14-15$ & Este trabajo \\
& $20-36$ & $5-7$ & $16-20$ & Hustedt 1959 \\
& 21 & 6 & $17-21$ & Rivera 1968 \\
& $20-36$ & $5-7$ & $16-20$ & Cocquyt 2004 \\
& $6,2-14,3$ & $2,4-4,0$ & $16-20$ & Este trabajo \\
\hline
\end{tabular}
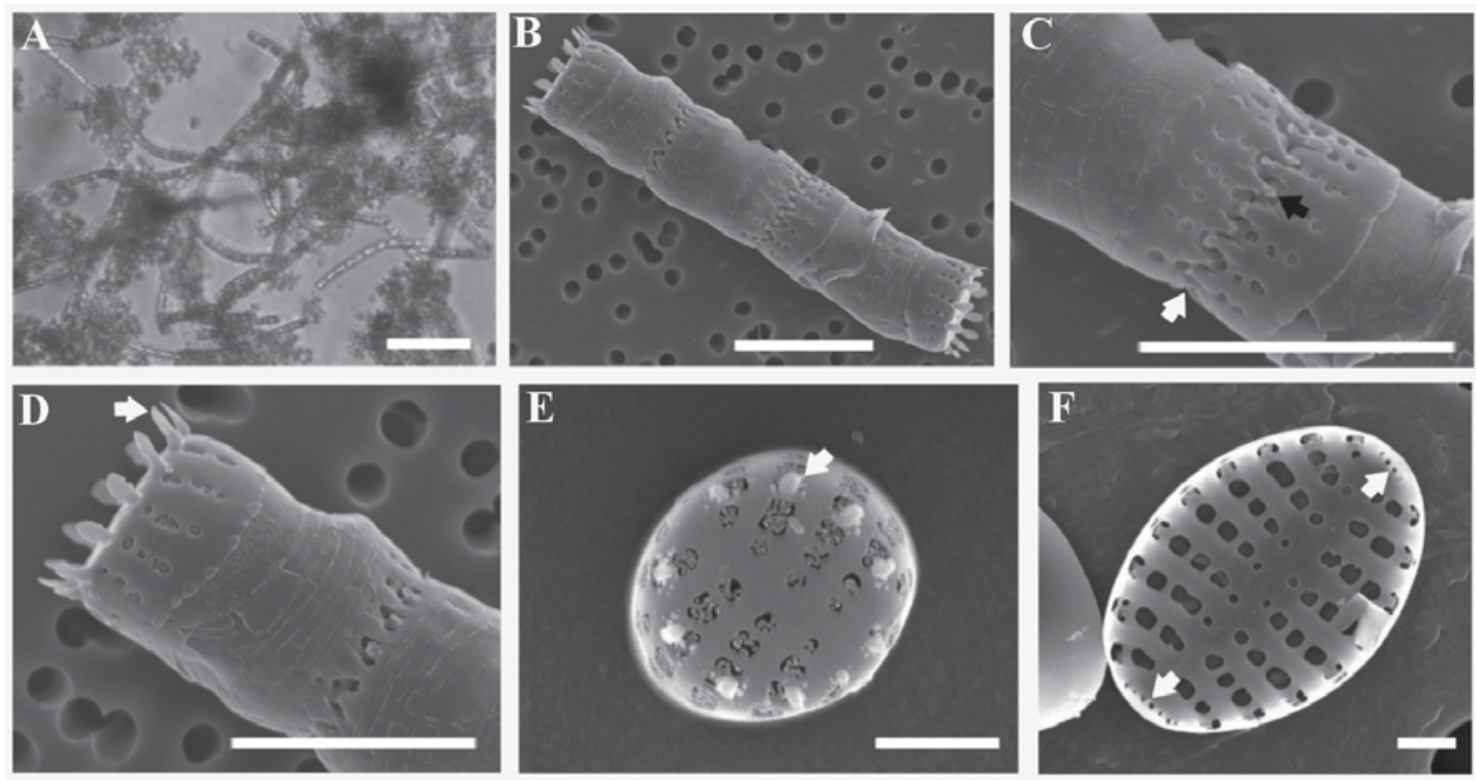

Figura 3. Pseudostaurosira trainorii en sedimentos de Concepción. ML: A; MEB: B-F. A. Cadenas en capa floculenta. B. Cadena de tres células. C. Detalle de la unión entre dos valvas adyacentes (flecha blanca) y pequeños discos aplanados en las areolas asociadas a las espinas (flecha negra). D. Valva terminal en la cadena. Note las espinas (flecha). E. Vista valvar externa de un ejemplar pequeño de forma redondeada. Nótese las espinas ubicadas en cada estría (flecha) y las areolas con velum ramificado. F. Vista valvar interna mostrando campo de poros apical en cada extremo valvar (flechas). Escalas: $\mathrm{A}=40 \mu \mathrm{m} ; \mathrm{B}-\mathrm{D}=5 \mu \mathrm{m}, \mathrm{E}, \mathrm{F}=1 \mu \mathrm{m}$.

FIGURE 3. Pseudostaurosira trainorii from cultured sediments off Concepción. LM: A; SEM: B-F. A. Chains from the flocculent layer. B. A chain of three cells. C. Detail of the junction between two adjacent valves (white arrow) and small flattened discs on areolae immediately beneath spines (black arrow). D. Terminal valve of the chain. Note the spines (arrow). E. External view of a small and rounded valve. Note the spines located in correspondence with each stria (arrow) and areolae with branched velum. F. Internal view of the valve showing the apical pore field at each apex (arrows). Scales: $\mathrm{A}=40 \mu \mathrm{m}$; $\mathrm{B}-\mathrm{D}=5 \mu \mathrm{m}, \mathrm{E}, \mathrm{F}=1 \mu \mathrm{m}$. 
Cultivo de diatomeas y dinoflagelados en sedimentos marinos: SÁnCHEZ, G. ET AL.

proyecciones en forma de disco que nacen en el borde de las areolas del manto, siendo muy notorias en la areola asociada a la espina. En nuestros ejemplares se observan estas proyecciones, pero no son tan evidentes (cabeza de flecha) (Fig. 3BD). El complejo "S. elliptica" se encuentra bajo estudio (Morales 2001, Edlund et al. 2006) e incluye varias especies de las cuales $P$. trainorii es una de ellas.

Esta especie ha sido caracterizada como una diatomea de agua dulce de distribución cosmopolita (Schumann 1867, Morales 2001, Edlund et al. 2006). Sin embargo, ha sido citada para el submareal (sobre rocas) del mar de "Bothnia" (Busse \& Snoeijs 2003), en sedimentos costeros del Golfo de Finlandia (Weckström \& Juggins 2005), y en sedimentos del Holoceno de las bahías de las islas Windmill, Antártida Este (Cremer et al. 2003). Esta especie no ha sido reportada anteriormente para Chile.
Pseudostaurosira sp.1 (Grunow) Williams \& Round 1987

(Fig. 4A-F)

Referencias: Williams \& Round 1987, p. 276.

Descripción: Frústulo rectangular en vista conectival (Fig. 4A); valvas más o menos heteropolares (Fig. 4D y F). Estrías uniseriadas compuestas por dos areolas redondas a ovoides, una localizada en la cara valvar y la otra sobre el manto valvar. Esternón estrechamente lanceolado (Fig. 4D y F). Campo apical de poros bien desarrollados en ambos polos, compuestos por varias filas de poros redondeados. Usualmente la depositación de minerales en los poros dan la apariencia de líneas paralelas en los extremos valvares (Fig. 4D, E y F). Espinas bien desarrolladas, con borde aserrado (Fig. 4C), localizadas en el borde entre la cara valvar y el manto (Fig. 4A, B, C y D), interrumpiendo la estría. Proceso labiado ausente.
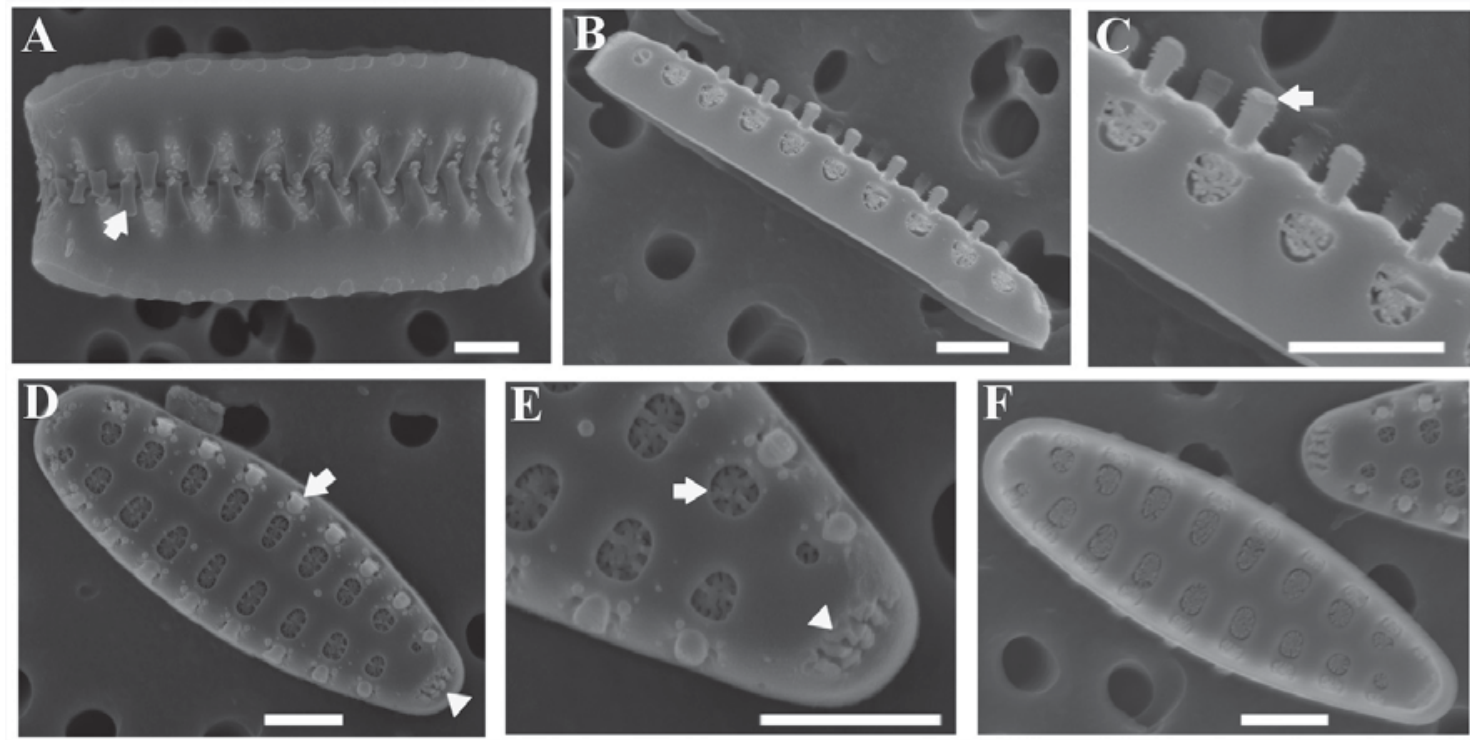

Figura 4. Pseudostaurosira sp.1 de sedimentos cultivados (Concepción). MEB: A-F. A. Valvas de células adyacentes, unidas con espinas (flecha). B. Valva en vista conectival. C. Detalle de valva. Nótese las areolas redondeadas y las espinas aserradas (flecha). D. Vista valvar externa. Nótese la forma ligeramente heteropolar de la valva; la ubicación de las espinas (flecha) y la presencia de un campo apical de poros en los extremos de la valva (cabeza de flecha). E. Detalle ápice valvar, vista externa. Nótese las areolas ovoides (flecha) y poros del campo apical (cabeza de flecha). F. Vista valvar interna. Escala: $1 \mu \mathrm{m}$.

FIGURE 4. Pseudostaurosira sp.1 from cultured sediments (Concepción). SEM: A-F. A. Valves of adjacent cells connected with spines (arrow). B. Single valve in girdle view. C. Detail of the valve. Note the rounded areolae and the serrated spines (arrow). D. External view of the valve. Note the slightly heteropolar shape, the location of the spines (arrow), and the presence of the apical pore field at each apex (arrowhead). E. Detail of the apex, external view. Note the ovoid shape of the areolae (arrow), and the apical pore field (arrowhead). F. Internal valve view. Scale: $1 \mu \mathrm{m}$. 
Este taxón se diferencia de Pseudostaurosira sp. 2 por las espinas, las cuales son prominentes y aserradas en Pseudostaurosira sp. 1, en tanto que en Pseudostaurosira sp. 2 son muy incipientes. Además, en la forma de las areolas y la placa de cierre.

Pseudostaurosira sp.2 (Grunow) Williams \& Round 1987

(Fig. 5A-G)

Referencias: Williams \& Round 1987, p. 276.

Descripción: Frústulos rectangulares en vista conectival (Fig. 5A). Valvas claviformes, extremos redondeados o subrostrados (Fig. 5C y F). Estrías uniseriadas compuestas por dos areolas elípticas a ovoides con barras longitudinales, una localizada en la cara valvar y la otra sobre el manto valvar; placa de cierre delicada y muy ramificada (Fig. 5D,
E y G). Esternón moderadamente ancho. Presencia de espinas, localizadas en el borde entre la cara valvar y el manto, sobre las estrías (Fig. 5B y E). Proceso labiado ausente; campo apical de poros presentes en cada extremo (Fig. 5D, E y G). También en esta especie se registran depósitos de minerales ubicados cercanos al ápice de la valva. Estos ejemplares presentan similitudes con Sarcophagodes delicatula Morales 2002, sin embargo en esta especie las espinas son incipientes y se hallan entre las estrías (com. pers. Morales 2007).

Este taxón se diferencia de Pseudostaurosira sp.1 por la forma y tamaño de las espinas, la forma de las areolas y la placa de cierre.

Algunas especies del género Pseudostaurosira son de difícil identificación; este género se diferencia de Staurosira por la naturaleza de las estrías, la forma del esternón y por el tamaño pequeño del campo apical de poros (Williams \& Round 1987).
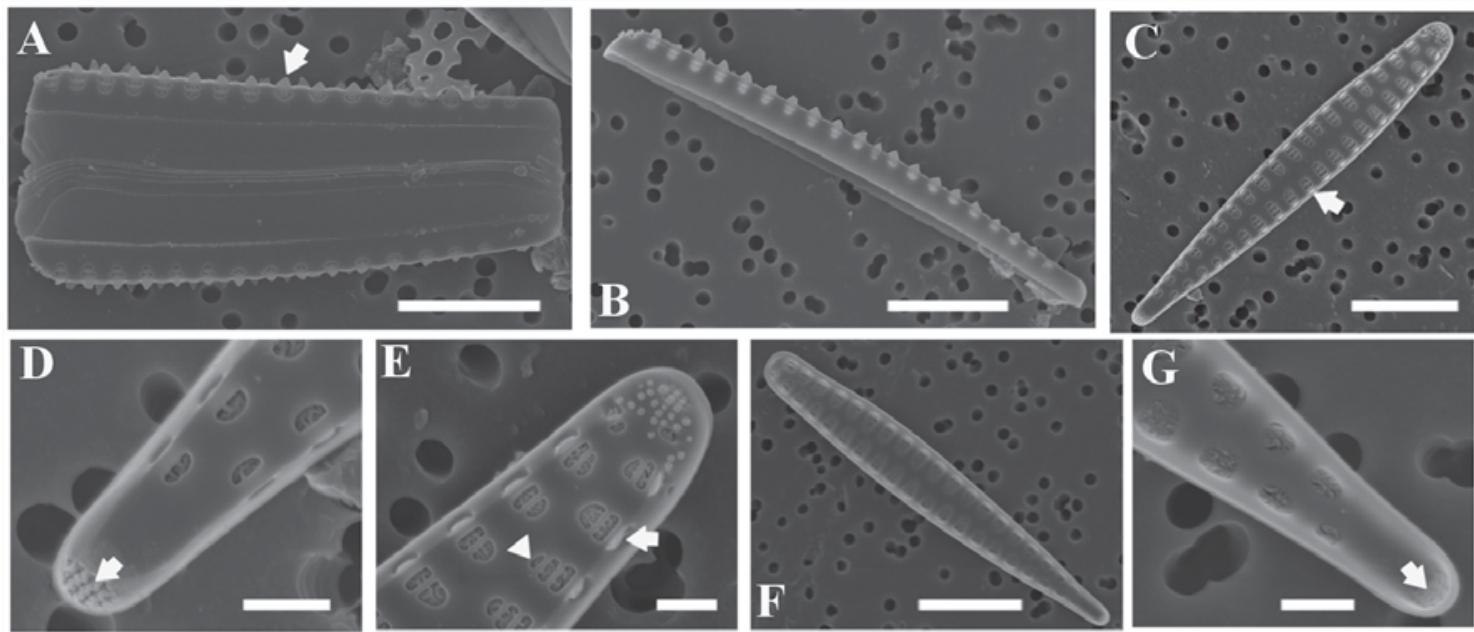

Figura 5. Pseudostaurosira sp. 2 de sedimentos cultivados (Concepción). MEB: A-G. A. Frústulo en vista conectival. Nótese espinas poco desarrolladas (flecha), valvocópula ancha y bandas del cíngulo angostas. B. Valva en vista conectival. C. Vista valvar externa. Nótese la forma claviforme de la valva, la ubicación de las espinas (flecha). D y E. Vista valvar externa a la altura de los dos ápices. D. Nótese el campo apical de poros (flecha). E. Note la forma elíptica de las areolas con barras (cabeza de flecha), la delicada placa de cierre y las espinas muy pequeñas sobre cada estría (flecha). F. Vista valva interna. G. Detalle del ápice valvar, vista interna, mostrando el campo apical de poros (flecha). Escalas: A-C, F=5 $\mu \mathrm{m}$; D, $\mathrm{E}, \mathrm{G}=1 \mu \mathrm{m}$.

Figure 5. Pseudostaurosira sp.2 from cultured sediments (off Concepción). SEM: A-G. A. Frustule in girdle view. Note the poorly developed spines (arrow), the broad valvocopula and the narrow bands of the cingulum. B. Valve in girdle view. C. External valve view. Note the claviform shape of the valve and the location of the spines (arrow). D and E. External valve view of the two apices. D. Note the apical pore field (arrow). E. Note the elliptical shape of the areolae with bars (arrowhead), the delicate closing plate, and the presence of very small spines on each stria (arrow). F. Internal view of the valve. G. Detail of valve apex, internal view, showing the apical pore field (arrow). Scales: A-C, F=5 $\mu \mathrm{m} ; \mathrm{D}, \mathrm{E}, \mathrm{G}=1 \mu \mathrm{m}$. 
Cultivo de diatomeas y dinoflagelados en sedimentos marinos: SÁnchez, G. ET AL.

Asimismo, algunas especies de Opephora se relacionan con Pseudostaurosira (Sundbäck 1987, Witkowski et al. 2000).

La única especie del género Pseudostaurosira reportada para sedimentos superficiales en las costas de Chile es la especie de agua dulce Pseudostaurosira brevistriata (Grunow in Van Heurck) D. M. Williams \& Round var. inflata (Pant.) M. B. Edlund (Romero \& Hebbeln 2003).

\section{Navicula pseudoreinhardtii Patrick 1959}

(Fig. 6A-E)

Referencias: Patrick 1959, p. 104, Lám. 7, fig. 9. Rivera \& Valdebenito 1979, p. 52, fig. 31.

Descripción: Valvas lanceoladas con extremos redondeados (Fig. 6A, B y C). Area axial muy angosta; área central tiene forma de moño, formada por el acortamiento irregular de las estrías. Rafe recto, filiforme; fisuras proximales cercanas (Fig. 6B). Estrías lineales, radiales y un poco curvadas cerca de la parte media de la valva, paralelas o levemente convergentes hacia los extremos (Fig. 6C y D); en la zona central a cada lado de la rafe se encuentra una estría más corta, sin embargo, estas dos estrías se encuentran en posición diagonal una respecto a la otra (Fig. 6E).

Navicula pseudoreinhardtii ha sido caracterizada como especie de agua dulce, habiéndose citado para Carolina del Sur, Florida (Hohn 1961). En la VIII Región del Bío-Bío se encontró en los ríos Chivilingo (rara), Laraquete (común) (Rivera \& Valdebenito 1979) y en el río Bío-Bío (Parra et al. 1993). El hecho de haberse desarrollado en medio salino estaría indicando que posiblemente corresponde a una especie mixohalina.
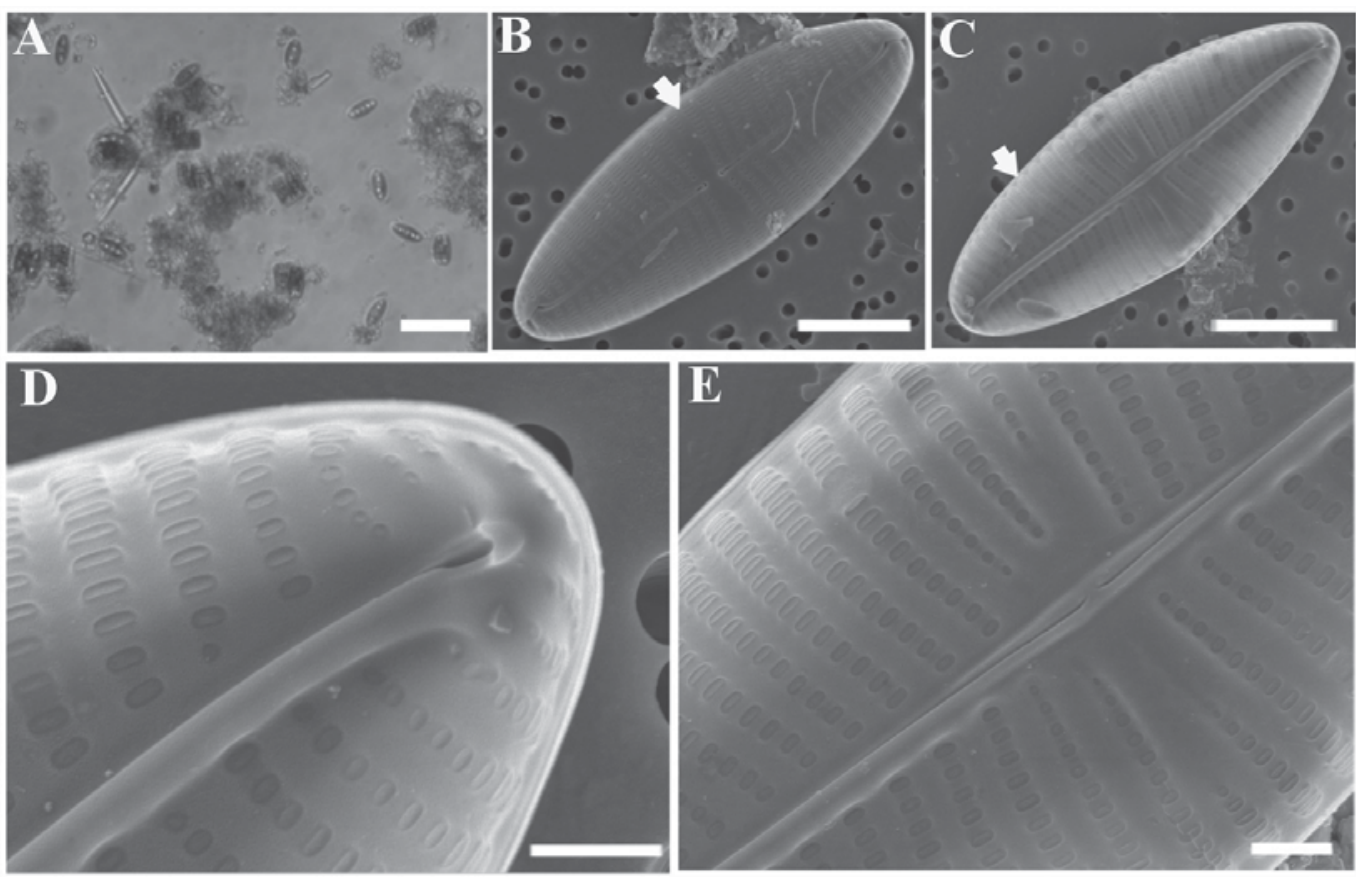

FIgURA 6. Navicula pseudoreinhardtii de sedimentos cultivados de la Bahía de Mejillones. ML: A; MEB: B-E. A. Vista general de las células en cultivo. B. Vista valvar externa. Nótese la forma del área central (flecha). C. Vista valvar interna. Nótese la estriación lineal de tipo radial (flecha). D. Detalle ápice valvar en vista interna; estrías levemente convergentes hacia el extremo valvar. E. Detalle área central en vista interna. Escalas: $\mathrm{A}=40 \mu \mathrm{m} ; \mathrm{B}, \mathrm{C}=5 \mu \mathrm{m}$; $\mathrm{D}$, $\mathrm{E}=1 \mu \mathrm{m}$.

FIGURE 6. Navicula pseudoreinhardtii cultured sediments of Mejillones Bay. LM: A. SEM: B-E. A. General view of cells in culture. B. External valve view. Note the shape of the central area (arrow). C. Internal valve view. Note the lineate, radial striae (arrow). D. Detail of the apex, internal view; striae slightly convergent toward the valve apex. E. Detail of the central area, internal view. Scales: $A=40 \mu \mathrm{m} ; \mathrm{B}, \mathrm{C}=5 \mu \mathrm{m} ; \mathrm{D}, \mathrm{E}=1 \mu \mathrm{m}$. 


\section{Stauroneis legleri Hustedt 1959}

(Fig. 7A-F)

Referencias: Hustedt 1931-59, p. 793, Fig. 1138; Rivera 1968, p. 71, Lám. 14, Fig. 6; Cocquyt 2004, p. 40 , Figs. $28-32$.

Descripción: Valvas lanceoladas, con extremos redondeados (Fig. 7A). Superficie valvar plana (Fig. 7A-D). Rafe recto, filiforme, con terminaciones centrales ensanchadas (Fig. 7C y D); extremos terminales curvados hacia el mismo lado (vista externa, Fig. 7C). Area axial angosta, linear; área central lisa, no ornamentada en forma de fascia que alcanza el margen valvar donde existe una corta estría marginal (Fig. 7B, C y E). Areolas alargadas longitudinalmente, en número de 20 y 16 en $10 \mu \mathrm{m}$ en extremos y centro de la valva, respectivamente (Fig. 7C y D). Nódulo central levemente ensanchado lateralmente (Fig. 7E y F).

Stauroneis legleri ha sido caracterizada como marina habiéndose citado para Gran Bretaña (Sims 1996). En Chile se encontró anteriormente con frecuencia "rara" en la Bahía de Concepción (Rivera 1968).
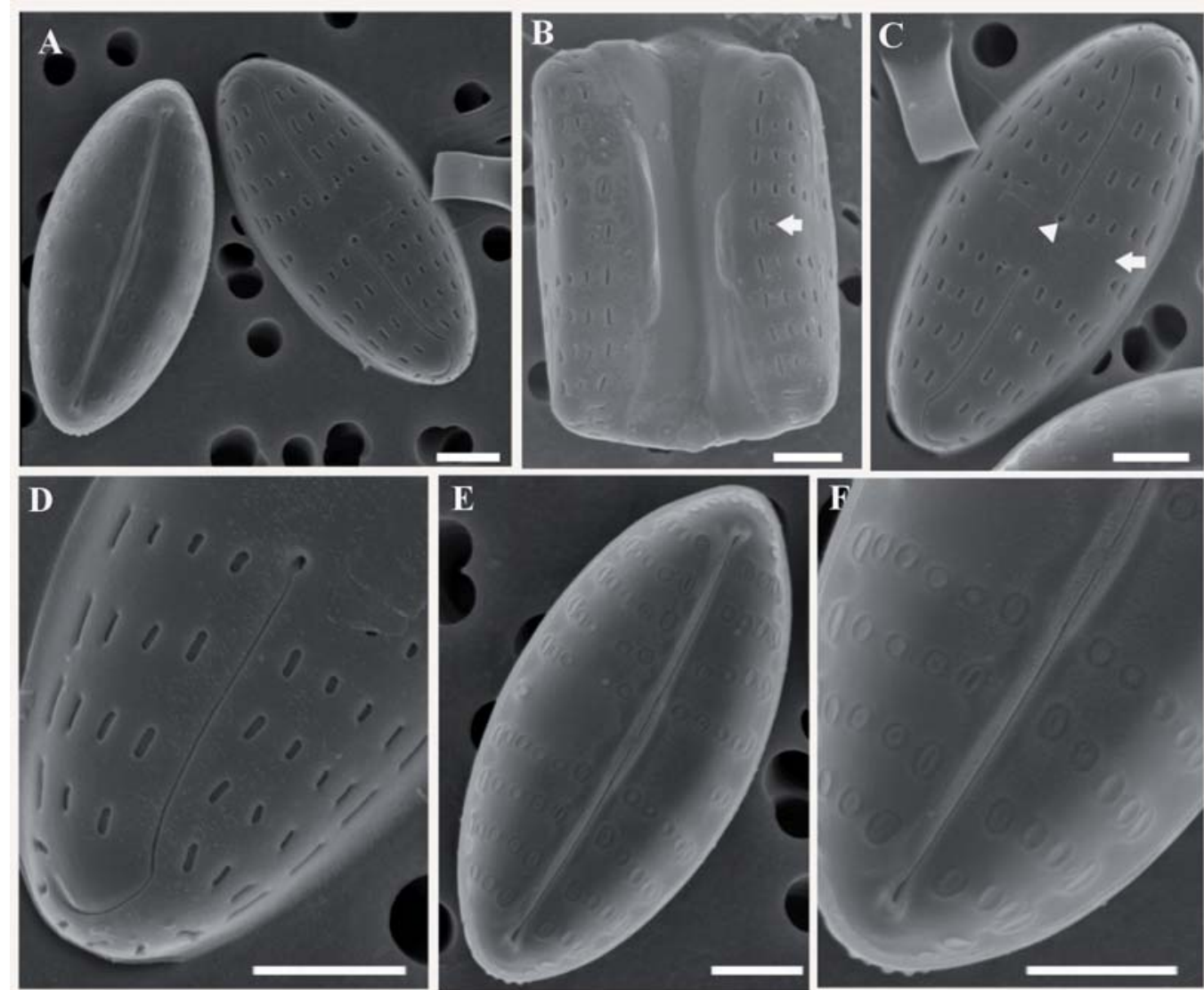

FIgURA 7. Stauroneis legleri. De sedimentos cultivados de Concepción. MEB: A-F. A. Vista valvar interna (izq.) y externa (der.). B. Vista conectival de célula. Nótese presencia de estría marginal en el centro de la valva (flecha). C. Vista valvar externa. Nótese presencia de fascia (flecha) y rafe con poros centrales ensanchados (cabeza de flecha). Rafe con extremos apicales curvados hacia el mismo lado. D. Detalle valva externa. Nótese las areolas alargadas longitudinalmente. E. Vista valvar interna. F. Detalle valva interna. Escalas: A=5 $\mu \mathrm{m}$; B-F=1 $\mu \mathrm{m}$.

FIGURE 7. Stauroneis legleri from cultured sediments off Concepción. SEM: A-F. A. Internal (left) and external (right) valve views. B. Cell in girdle view. Note the presence of a marginal stria at the valve center (arrow). C. External valve view. Note the presence of the fascia (arrow), and the central raphe pores (arrowhead). The terminal raphe endings are curved to the same side. D. Detail of the valve, external view. Note the slit-like areolae. E. Internal valve view. F. Detail of the internal valve. Scales: $\mathrm{A}=5 \mu \mathrm{m} ; \mathrm{B}-\mathrm{F}=1 \mu \mathrm{m}$. 
Cultivo de diatomeas y dinoflagelados en sedimentos marinos: SÁnCHEZ, G. ET AL.

\section{DISCUSION}

La germinación de diatomeas en incubaciones de sedimentos recientemente depositados, es el resultado de la multiplicación de células vegetativas y de la germinación de esporas de resistencia. El período de latencia de esporas de diatomeas y quistes de dinoflagelados depende de las condiciones del ambiente en los sedimentos (baja temperatura, oscuridad, disponibilidad de oxígeno, entre otros) y, posteriormente, del lugar de almacenamiento de las muestras (Hollibaugh et al. 1981, Anil et al. 2007). En nuestro estudio fueron las diatomeas pennadas las que se multiplicaron de forma abundante (Pseudostaurosira trainorii, Pseudostaurosira sp. 1, Pseudostaurosira sp. 2, Navicula pseudoreinhardtii y Stauroneis legleri), pese a que las principales diatomeas presentes en dichos sedimentos fueron Skeletonema japonicum y esporas de varias especies del género Chaetoceros. Cabe la pregunta ¿por qué estas especies no crecieron en cultivo en la abundancia esperada?

Frecuentemente, especies de los géneros Chaetoceros y Skeletonema son constituyentes importantes del ensamblaje de diatomeas depositadas en sedimentos marinos (e.g. McQuoid 2002, Romero \& Hebbeln 2003). En general, la viabilidad de diatomeas y dinoflagelados ha sido reportada en columnas de sedimentos de hasta $\sim 40 \mathrm{~cm}$ de profundidad, cuya edad osciló de unos cuantos meses a más de 55 años de depositación (Lewis et al. 1999, McQuoid et al. 2002, Anil et al. 2007). Las esporas de resistencia de diatomeas están fuertemente silificadas y pueden sobrevivir largos periodos en condiciones de oscuridad y baja temperatura durante los cuales mantienen niveles muy bajos de respiración (Peters \& Thomas 1996). Sin embargo, se ha observado en condiciones de cultivo, que la reactivación de las esporas requiere varios días para germinar ya que después de largos periodos de latencia las células están en un estado metabólicamente débil (French \& Hargraves 1980, Anil et al. 2007). McQuoid et al. (2002) registraron la germinación de especies de Chaetoceros y Skeletonema a partir del décimo día de cultivo. Dado que en nuestros experimentos los organismos incubados tuvieron tiempo suficiente para la germinación (25 días), se infiere que otros factores (e.g., condiciones ambientales, abundancia, tiempo de sobrevivencia, variabilidad en la respuesta de diferentes especies) podrían haber actuado durante el periodo de latencia y posterior germinación.

Se sabe que el tiempo de sobrevivencia de los estados de resistencia y su viabilidad varía entre especies (Hollibaugh et al. 1981, Lewis et al. 1999). McQuoid et al. (2002) informaron para sedimentos superficiales $(0$ a $2 \mathrm{~cm}$ ) del Fiordo Koljö en la costa oeste de Suecia, donde especies de Chaetoceros y Skeletonema constituyen $\sim 58 \%$ del total de diatomeas, que la viabilidad de estas especies es superior al $40 \%$. Sin embargo, en estos sedimentos sólo una proporción de la población germinó durante los experimentos de cultivo ( $S$. costatum $37 \%$, C. diadema $15 \%$, C. socialis $4 \%$ у $C$. didymus $0,3 \%$ ), confirmando que aunque la viabilidad sea alta, ésta no garantiza la germinación de las células. Otros trabajos muestran que en general hay una relación directa entre la abundancia de diatomeas, su viabilidad y su germinación (Anil et al. 2007). A medida de que pasa el tiempo el porcentaje de germinación disminuye y en algunos casos se ha observado que después de dos años las esporas de especies como $C$. diadema, $C$. didymus y C. vanheurckii ya no germinan (Hollibaugh et al. 1981, McQuoid et al. 2002, Anil et al. 2007).

Con relación a la germinación de los quistes de dinoflagelados en nuestros experimentos, ésta fue escasa y representada sólo por Woloszynskia sp. Nuestros ejemplares presentaron vesículas alveolares visibles en la superficie celular y en la acrobase (Fig. 2G y H), características típicas del género (Thompson 1951). La sistemática de todos los dinoflagelados woloszynskioides está en revisión (Moestrup \& Daugbjerg 2007), por lo tanto la afiliación de este taxón al género Woloszynskia y su descripción como una nueva especie, esperan nuevos avances en el conocimiento taxonómico de este grupo de dinoflagelados. En estudios previos y con fines taxonómicos, Lembeye (2004) cultivó sedimentos marinos del sur-austral de Chile $\left(43^{\circ} \mathrm{y}\right.$ $54^{\circ} \mathrm{S}$ ) logrando la germinación de tres especies de Protoceratium y dos especies de Scrippsiella.

Los resultados de estudios previos en cuanto al efecto de la concentración de oxígeno en la germinación de especies fitoplanctónicas son contradictorios. Por ejemplo, Hollibaugh et al. (1981) y Kremp \& Anderson (2000) reportan baja viabilidad y germinación de esporas y quistes en condiciones anóxicas. McQuoid (2002) concluye que la baja concentración de oxígeno en aguas de fondo en un fiordo de la costa oeste de Suecia afecta negativamente la sobrevivencia de $S$. costatum. 
Gayana Bot. 66(2), 2009

Por otro lado, Blanco (1990) y McQuoid et al. (2002) sugieren que condiciones bajas de oxígeno prolongan la sobrevivencia de dinoflagelados $\mathrm{y}$ diatomeas en sedimentos, principalmente debido a que estos ambientes impiden o limitan el desarrollo de la fauna bentónica y su presión de pastoreo.

En este trabajo las estaciones de muestreo presentan niveles bajos de oxígeno de las aguas de fondo: en la Bahía de Mejillones se han reportado valores inferiores a $0,3 \mathrm{ml} \mathrm{L}^{-1}$ a lo largo del año (Valdés et al. 2000), mientras que en la Bahía de Concepción los valores varían estacionalmente oscilando entre $<0,1 \mathrm{a} \sim 2,6 \mathrm{ml} \mathrm{L}^{-1}$ (Escribano et al. 2007). En ambos casos la concentración de oxígeno alcanza niveles subóxicos/anóxicos, que son condiciones extremas que podrían afectar negativamente la viabilidad de las esporas de resistencia y quistes.

En la Figura 8 se presentan los valores de oxígeno disuelto de las aguas cercanas al fondo para el sitio de muestreo durante los meses de muestreo de este estudio. Es interesante resaltar que cuatro de las cinco especies que crecieron abundantemente en cultivo (S. legleri, P. trainorii, Pseudostaurosira sp. 1 y Pseudostaurosira sp. 2) provienen de la capa floculenta del mes de septiembre(Tabla II), pudiéndose asumir que estaban recientemente depositadas, incrementando posiblemente su viabilidad. Además, para el mes de septiembre se registró en la columna de agua un incremento importante en la proporción de las diatomeas pennadas (Serie de Tiempo FONDAPCOPAS 2006) coincidente con un aumento sustancial en la concentración de oxígeno de fondo ( 1,2 $\mathrm{ml} \mathrm{L}^{-1}$; Fig. 8). Una situación diferente se dio con las especies de Skeletonema y Chaetoceros, las cuales presentaron sus máximas abundancias en noviembre y diciembre cuando los niveles de oxígeno fueron muy bajos $\left(<0,5 \mathrm{ml} \mathrm{L}^{-1}\right)$ (Fig. 8). A su vez, y a pesar que las incubaciones también provienen de la capa floculenta (Tabla II), ésta corresponde a los meses de verano con

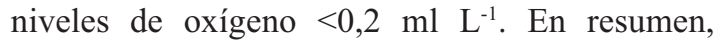
los datos presentados sugieren que células recientemente depositadas en el fondo marino, una alta abundancia de ellas y unas condiciones de oxigenación favorables, están directamente relacionadas con la germinación exitosa de las diatomeas pennadas, mientras que la baja disponibilidad de oxígeno afecta negativamente a Skeletonema y Chaetoceros, a pesar de una alta abundancia en el sedimento.

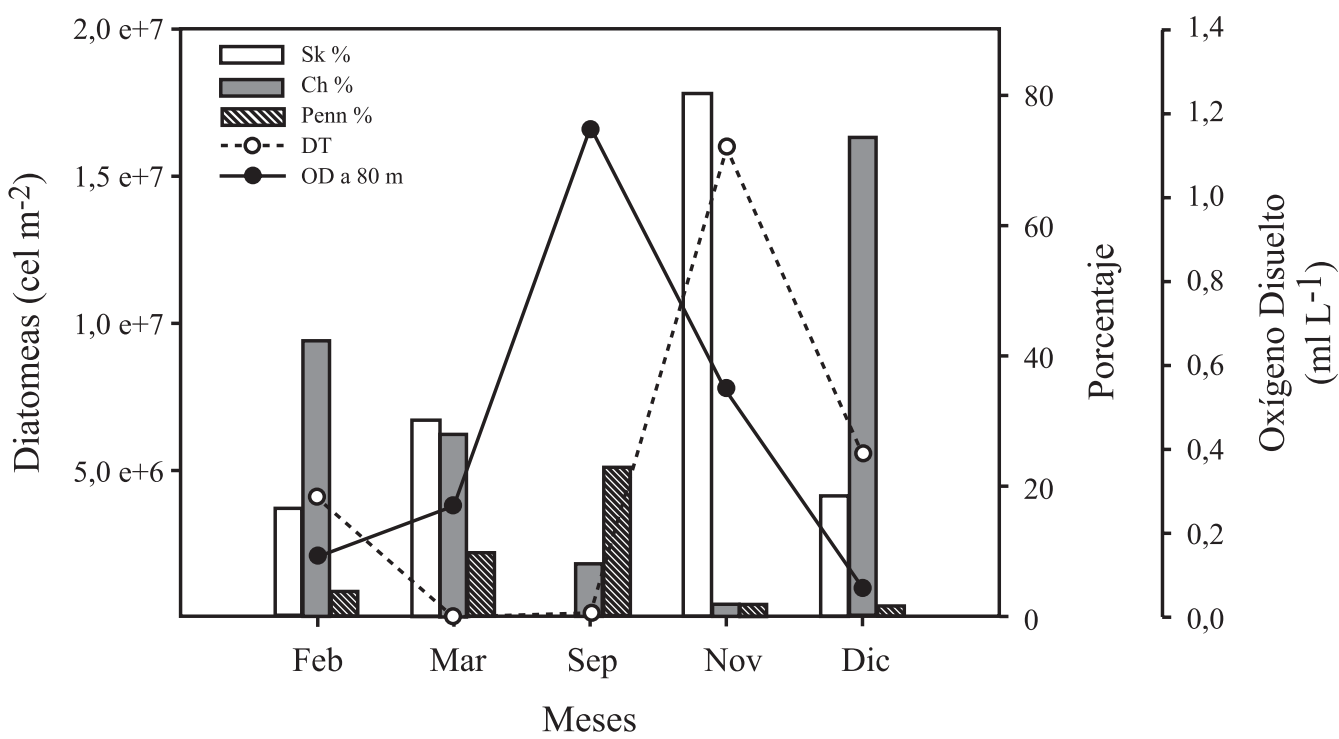

Figura 8. Abundancia integrada de diatomeas en los primeros $30 \mathrm{~m}$ de la columna de agua (cel $\left.\mathrm{m}^{-2}\right)$ de Concepción durante cinco meses del año 2005. Contribución relativa (\%) de Skeletonema japonicum, Chaetoceros spp. y diatomeas pennadas al total de diatomeas (DT). Concentración de oxígeno disuelto $\left(\mathrm{ml} \mathrm{L}^{-1}\right)$ en el agua cerca del fondo $(\sim 80 \mathrm{~m})$.

FIGURE 8. Diatom abundance, integrated over the upper $30 \mathrm{~m}$ of the water column (cell $\mathrm{m}^{-2}$ ) at Concepción, during five months of 2005. Relative contribution (\%) of Skeletonema japonicum, Chaetoceros spp. and pennate diatoms to the total diatoms (DT). Concentration of bottom water dissolved oxygen $\left(\mathrm{ml} \mathrm{L}^{-1}\right)$ at $80 \mathrm{~m}$. 
Este estudio representa un primer intento de cultivo de estados de resistencia de diatomeas en sedimentos de la plataforma continental chilena, donde se obtuvieron resultados positivos en germinación y crecimiento. Sin embargo, es necesario hacer ensayos similares con sedimentos frescos de diferentes estaciones del año, con el fin de evaluar en el tiempo los factores ambientales que afectan la viabilidad y germinación de esporas y quistes, así como los efectos de las condiciones de almacenamiento y refrigeración de las muestras como ha sido observado en estudios previos (Anil et al. 2006).

\section{AGRADECIMIENTOS}

Agradecemos a la Fundación Andes (Proyecto $\mathrm{N}^{\mathrm{o}}$ E13-852) por el financiamiento de la estadía de estudio de la primera autora en la Stazione Zoologica y al Servicio de Microscopía Electrónica de la misma. Al financiamiento parcial del Centro FONDAP-COPAS, Universidad de Concepción. A los Drs. Eduardo Morales y Mark Edlund por sus aportes en taxonomía y a dos revisores anónimos por las sugerencias que contribuyeron a mejorar este trabajo.

\section{BIBLIOGRAFIA}

Amato, A., L. Orsini, D D’Alelio \& M. Montresor. 2005. Life cycle, size reduction patterns, and ultrastructure of the pennate planktonic diatom Pseudo-nitzschia delicatissima (Bacillariophyceae). Journal of Phycology 41: 542-556.

Anderson, D., F. Fukuyo \& K. Matsuoka. 1995. Cyst methodologies. In: Manual on Harmful Marine Microalgae. Manual and Guides IOC-UNESCO $\mathrm{N}^{\mathrm{o}}$ 33: 229-249.

Anil, A., S. Mitbavkar, M. D'Silva, S. Hegde, P. D'Costa, S. Meher \& D. Banerjee. 2007. Effect of ageing on survival of benthic diatom propagules. Journal of Experimental Marine Biology and Ecology 343: 37-43.

Archibald, R. 1983. The diatoms of the Sundays and Great Fish Rivers in the Eastern Cape Province of South Africa. Bibliotheca Diatomologica 1:5-362.

Awad, A., C. Clarke, L. Greyling, R. Hilliard, P. Polglaze \& S. RaAymakers. 2004. Ballast water risk assesment, Port of Saldanha Bay, Republic of South Africa, November 2003: Final Report. GloBallast Monograph Series, 13.
IMO, London, $63 \mathrm{pp}$.

BlanCo, J. 1990. Cysts germination of two dinoflagellates species from Galicia (NW Spain). Scientia Marina 54: 287-291.

Bolch, C. 1997. The use of sodium polytungstate for the separation and concentration of living dinoflagellate cysts from marine sediments. Phycologia 36: 472-478.

Busse, S. \& P. Snoeiss. 2003. Gradient responses of diatom communities in the Bothnian Sea (northern Baltic Sea), with emphasis on responses to water movement. Phycologia 42: 451-464.

CÁceres, M. \& D. Arcos. 1991. Variabilidad en la estructura espacio-temporal de un área de surgencia frente a la costa de Concepción, Chile. Investigaciones Pesqueras (Chile) 36: 27-38.

Cocquyt, C. 2004. Staurophora caljonii spec. nov. (Bacillariophyceae, Anomoeoneidaceae), a new halophilic diatom species from sub-recent lake deposits in Kenya. Hydrobiologia 511: 37-46.

Cremer, H., D. Roberts, A. McMinn, D. Gore \& M. Melles. 2003. The Holocene Diatom Flora of Marine Bays in the Windmill Islands, East Antarctica. Botanica Marina 46: 82-106.

Cupp, E. 1943. Marine plankton diatoms of the west coast of North America. Bulletin, Scripps Institution of Oceanography 5: 1-238.

Edlund, M., E. Morales \& S. Spaulding. 2006. The type and taxonomy of Fragilaria elliptica Schumann, a widely misconstrued taxa. In: A. Witkowski (ed.) Proceedings of the Eighteenth International Diatom Symposium. 53-59 pp.

Escribano, R., P. Hidalgo, H. GonzÁlez, R. Giesecke, R. Riquelme-Bugueño \& K. Manríquez. 2007. Seasonal and inter-annual variation of mesozooplankton in the coastal upwelling zone off central-southern Chile. Progress in Oceanography. Special Issue The Structure and functioning of the coastal upwelling in Central/ Southern Chile 75: 470-485.

FonseCA, T. \& M. Farías. 1987. Estudio del proceso de surgencia en la costa chilena utilizando percepción remota. Investigaciones Pesqueras (Chile) 34: 33-46.

French, F. \& P. Hargraves. 1980. Physiological characteristics of plankton diatom resting spores. Marine Biology Letters 1: 185-195.

GARrison, D. 1981. Monterey Bay phytoplankton. II. Resting spore cycle in coastal diatom populations. Journal of Plankton Research 3: 137-156.

González, H., E. Menschel, C. Aparicio \& C. Barrí. 2007. Spatial and temporal variability of microplankton and detritus, and their export to the shelf sediments in the upwelling area off Concepción, Chile $\left(\sim 36^{\circ} \mathrm{S}\right)$, during 20022005. Progress in Oceanography. Special Issue The Structure and functioning of the coastal upwelling in Central/Southern Chile 75: 435-451.

GonzÁlez, M., O. Parra \& A. Cifuentes. 1995. Técnicas 
Gayana Bot. 66(2), 2009

de cultivo de microalgas en laboratorio. En: K. Alvear, M. Ferrario, E. Oliveira \& E. Sar (eds.), pp. 219-250. Manual de métodos ficológicos. Universidad de Concepción. Editorial Aníbal Pinto S. A., Concepción, Chile, 863 pp.

Gutiérrez, D., V. Gallardo, S. Mayor, C. Neira, C. Vásquez, J. Sellanes, M. Rivas, A. Soto, F. Carrasco \& M. Baltazar. 2000. Effects of dissolved oxygen and organic matter reactivity on macrofaunal bioperturbation potencial in sublitoral bottoms off central Chile during 19971998 El Niño. Marine Ecology Progress Series 202: 81-99.

Hargraves, P. \& F. French. 1975. Observations on the survival of diatom resting spores. Nova Hedwigia Beihefte 53: 229-238.

Hollibaugh, J., D. Seibert \& W. Thomas. 1981. Observations on the survival and germination of resting spores of three Chaetoceros (Bacillariophyceae) species. Journal of Phycology 17: 1-9.

HoHn, M. 1961. The relationship between species diversity and population density in diatom populations from silver springs, Florida. Transactions of the American Microscopical Society 80: 140-165.

Hustedt, F. 1930. Die Kieselalgen Deutschlands, Österreichs und der Schweiz. L. Rabenhorst Kryptogamen-Flora 7: 1-920.

Hustedt, F. 1931-1959. Die Kieselalgen Deutschlands, Österreichs und der Schweiz. L. Rabenhorst Kryptogamen-Flora 7: 1-925.

Kelly, M., H. Bennion, E. Cox, B. Goldsmith, J. Jamieson, S. Juggins, D. Mann \& R. Telford. 2005. Common freshwater diatoms of Britain and Ireland: an interactive key. Environment Agency, Bristol. Fuente recurso electrónico: http://craticula.ncl.ac.uk/EADiatomKey/html/ index.html. Revisado: diciembre 2, 2007.

Kremp, A. \& D. Anderson. 2000. Factors regulating germination of resting cysts of the spring bloom dinoflagellate Scrippsiella hangoei from the northern Baltic Sea. Journal of Plankton Research 22: 1311-1327.

Lembeye, G. 2004. Distribución de quistes de Alexandrium catenella y otros dinoflagelados en sedimentos de la zona sur-austral de Chile. Ciencia y Tecnología del Mar 27: 21-31.

Lewis, J., J.D. Dodge \& P. Tett. 1984. Cyst-theca relationships in some Protoperidinium species (Peridiniales) from Scottish sea lochs. Journal of Micropaleontology 3: 25-34.

Lewis, J., A. HARris, K. Jones \& R. Edmonds. 1999. Longtime survival of marine planktonic diatoms and dinoflagellates in the sediment samples. Journal of Plankton Research 21: 343-354.

Marcus, N. \& F. Boero. 1998. Minireview: The Importance of Benthic-Pelagic Coupling and the Forgotten Role of Life Cycles in Coastal Aquatic Systems. Limnology and Oceanography 43: 763-768.
Marín, V., L. Rodríguez, L. Vallejo, J. Fuenteseca \& E. OyARCE. 1993. Efectos de la surgencia costera sobre la productividad primaria primaveral de Bahía Mejillones del Sur (Antofagasta, Chile). Revista Chilena de Historia Natural 66: 479-491.

Matsuoka, K. 1988. Cyst-theca relationships in the diplopsalid group (Peridiniales, Dinophyceae). Review of Palaeobotany and Palynology 56: 95-122.

Matsuoka, K. \& Y. Fukuyo. 2000. Technical guide for modern dinoflagellate cyst study. WESTPACHAB/WESTPAC/IOC. 77 p.

McQuord, M. 2002. Pelagic and benthic environmental controls on the spatial distribution of a viable diatom propagule bank on the Swedish West coast. Journal of Phycology 38: 881-893.

McQuoid, M. \& L. Hobson. 1995. Importance of resting stages in diatom seasonal succession. Journal of Phycology 31: 44-50.

McQuoid, M. \& L. Hobson. 1996. Diatom resting stages. Journal of Phycology 32: 889-902.

McQuoId, R., A. GodHE \& K. NordBerg. 2002. Viability of phytoplankton resting in the sediments of a coastal Swedish fjord. European Journal of Phycology 37: 191-201.

Moestrup, Ø. \& N. DaugbJerg. 2007. On dinoflagellate phylogeny and classification. In: J. Brodie \& J. Lewis (eds.), pp. 215-230. Unravelling the algae: the past, present, and future of algal systematics. CRC Press, New York.

Morales, E. 2001. Morphological studies in selected fragilarioid diatoms (Bacillariophyceae) from Connecticut waters (U.S.A.). Proceedings of the Academy of Natural Sciences of Philadelphia 151: 105-120.

Morales, E. 2002. Studies in selected fragilarioid diatoms of potential indicator value from Florida (USA) with notes on the genus Opephora Petit (Bacillariophyceae). Limnologica 32: 102-113.

Morales, C., S. Hormazábal \& J. Blanco. 1999. Interannual variability in the mesoscale distribution of the depth of the upper boundary of the oxygen minimum layer off northern Chile (18-24S): Implications for the pelagic system and biogeochemical cycling. Journal of Marine Research 57: 909-932.

Parra, O., S. Basualto, R. Urrutia, D. Avilés \& P. Rivera. 1993. Composición taxonómica del fitoplancton y fitobentos del Río Bio-Bío, Concepción, Chile. En: F. Faranda \& O. Parra (eds.). Evaluación de la calidad del agua y ecología del sistema limnético y fluvial del Río Bio-Bío. Serie Monografías Científicas EULA 12: $189-216$.

PATRICK, R. 1959. New species and nomenclatural changes in the genus Navicula (Bacillariophyceae). Proceedings of the Academy of Natural Sciences of Philadelphia 111: 91-108

Peters, E. \& D. Thomas. 1996. Prolonged darkness and diatom mortality I: Marine Antarctic species. 
Cultivo de diatomeas y dinoflagelados en sedimentos marinos: SÁnCHEZ, G. ET AL.

Journal of Experimental Marine Biology and Ecology 207: 25-41.

Rivera, P. 1968. Sinopsis de las diatomeas de la Bahía de Concepción, Chile. Gayana Botánica 18: 1-112.

Rivera, P. \& H. Valdebenito. 1979. Diatomeas recolectadas en las desembocaduras de los ríos Chivilingo, Laraquete y Carampangue, Chile. Gayana Botánica 35: 1-97.

Romero, O. \& D. Hebbeln. 2003. Biogenic silica and diatom thanatocoenosis in surface sediments below the Peru Chile Current: controlling mechanisms and relationship with productivity of surface waters. Marine Micropaleontology 48: 71-90.

Romero, O., D. Hebbeln \& G. Wefer. 2001. Temporal and spatial variability in export production in the SE Pacific Ocean: evidence from siliceous plankton fluxes and surface sediment assemblages. DeepSea Research 48: 2673-2697.

Round, F., R. CRAwFord \& M. MANn. 1990. The diatoms, biology and morphology of the genera. Cambridge University Press, Cambridge, $747 \mathrm{pp}$.

SAlgado, P. 2004. Registro histórico reciente de quistes de dinoflagelados productores de floraciones algales nocivas (fan) en sedimentos marinos del sur de Chile, X Región. Tesis pregrado, Biología Marina, Universidad de Concepción, Chile, 63 pp.

Schrader, H. \& R. Gersonde. 1978. Diatoms and silicoflagellates in the eight meters section of the lower Pliocene on Campo Rossello. Utrecht Micropaleontological Bulletin 17: 129-176.

Schumann, J. 1867. Preussische Diatomeen. Schriften der Königlichen Physikalisch-Ökonomischen Gesellschaft zu Königsberg 8: 37-68.

Sims, P. (ed.). 1996. An Atlas of British Diatoms, Biopress Limited, Bristol, England, $601 \mathrm{pp}$.

Snoeis, I. \& N. Balashova (eds.). 1998. Intercalibration and distribution of diatom species in the Baltic Sea. Baltic Marine Biologists Publication 16(5), $144 \mathrm{pp}$.

Strub, P., J. Mesias, V. Montecino, J. Rutlant \& S. SALINAS. 1998. Coastal ocean circulation of Western South America. In: A. Robinson \& K. Brink (eds.). The global coastal ocean: the sea. Wiley, New York, 273-314 pp.

SundBÄCK, K. 1987. The epipsammic marine diatom Opephora olsenii Möller. Diatom Research 2: 241-249.

Tomas, A. (ed.). 1997. Identifying Marine Phytoplankton. Academic Press, San Diego, California, USA, $858 \mathrm{pp}$.

Thompson, R. 1951. A new genus and new records of fresh-water Pyrrophyta in the Desmokontae and Dinophyceae. Lloydia 13: 277-299.

Valdés, J., L. López, S. Lomónaco \& L. Ortlieb. 2000. Condiciones paleoambientales de sedimentación y preservación de materia orgánica en bahía Mejillones del Sur $\left(23^{\circ} \mathrm{S}\right)$, Chile. Revista de Biología Marina y Oceanografía 35: 169-180.

Wall, D. \& B. Dale B. 1968. Modern dinoflagellate cysts and evolution of the Peridiniales. Micropaleontology 14: 265-304.

Weckström, K. \& S. Juggins. 2005. Coastal diatomenvironment relationships from the Gulf of Finland, Baltic Sea. Journal of Phycology 42: 21-35.

Williams, D. \& F. Round. 1987. Revision of the genus Fragilaria. Diatom Research 2: 267-88.

Witkowski, A., H. Lange-Bertalot \& D. Metzeltin. 2000. Diatom flora of marine coast I. Iconographia diatomologica annotared diatom micrographs. Diversity-taxonomy-identification 7. H. LangeBertalot (ed.). Gantner Verlag K, Königstein, Germany, 925 pp.

Recibido: 28.07 .08

Aceptado: 15.01 .09 